\title{
Design of Catechin-based Carbon Nanodots as Facile Staining Agents of Tumor Cells
}

\author{
Yaung Kwee ${ }^{1,2}$, Alfinda Novi Kristanti ${ }^{1}$, Nanik Siti Aminah ${ }^{1}$, and Mochamad Zakki Fahmi ${ }^{1,3, *}$ \\ ${ }^{1}$ Department of Chemistry, Airlangga University, Kampus C Mulyorejo, Surabaya 60115, Indonesia \\ ${ }^{2}$ Department of Chemistry, University of Mandalay, University Drive, $73^{\text {rd }}$ Mandalay, Myanmar
}

${ }^{3}$ Supramodification Nano-micro Engineering Laboratory, Airlangga University, Kampus C Mulyorejo, Surabaya 60115, Indonesia

\section{*Corresponding author:}

email:m.zakki.fahmi@fst.unair.ac.id

Received: October 2, 2019

Accepted: January 3, 2020

DOI: $10.22146 /$ ijc.50327

\begin{abstract}
Carbon nanodots (CNDs) have widely received great attention as a result of favorable optical, electrical, optoelectrical, biocompatible, and non-toxic properties that these nanoparticles possess. However, the exploration of nanoparticles from natural raw material is still limited. In the present work, carbon dots were produced from catechin isolated from Uncaria gambir through a simple and facile process. Carbon nanodots were produced by the pyrolysis process of catechin, which allowed it for carbonization. Owing to its unique properties, such as photoluminescence with an emission peak at $500 \mathrm{~nm}\left(\lambda_{\text {ex }}=\right.$ $380 \mathrm{~nm}$ ), average size diameter of about $5 \mathrm{~nm}$ and non-toxic properties, Cat-CNDs were incredibly potential for staining targeted tumor cells. The staining ability shown by confocal microscopy observations showed their green fluorescence images which meant that the CNDs easily penetrated HeLa cells via endocytosis. The resulting CNDs which were analyzed using several significant techniques proved that the prepared Cat-CNDs were tremendously dispersible and water-soluble, had good colloidal stability, excellent biocompatibility, favorable hydrophilicity, high photostability, and were non-toxic.
\end{abstract}

Keywords: Uncaria gambir; catechin; carbon nanodots; staining tumor cells

\section{- INTRODUCTION}

Gambir is one of the most important economical natural products in which Indonesia is the world's largest exporter, currently supplying $80 \%$ of the global market [1]. Moreover, it is a well-known and cost-effective plant, and considered as a promising medicinal plant that is found in Southeast Asian regions such as in West Sumatera of Indonesia and in the Peninsula of Malaysia. The family of the genus Uncaria is Rubiaceae, containing approximately 34 species, which abundantly grow in tropical regions of Southeast Asia, Africa, and South America [2-5]. The hooks of Uncaria gambir are conventionally prepared for the treatment of wounds, ulcers, fever, asthma, rheumatism, hyperpyrexia, hypertension, headaches, gastrointestinal illness, and bacterial or fungal infections [6-9]. Catechin, a polyphenolic compound, can be isolated from Uncaria gambir as a particular compound [10-11]. There have been reports on the pharmacological uses of catechin to enhance mental and behavioral symptoms of dementia that includes dementia with Lewy bodies, aggressiveness in patients with Alzheimers, agitation, hallucinations, and other forms of senile dementia [12-13].

In 2004, carbon dots (CDs) were accidentally discovered during the separation and purification of the single-walled carbon nanotubes and became a potentially new component of fluorescent carbon material with a diameter in the range of below $10 \mathrm{~nm}$. Subsequently, many studies regarding the nature of CDs have been developing at a great rate [14]. Consequently, there are currently many exploratory methods for the potent fabrication of fluorescent CNDs, such as electrochemical oxidation, chemical oxidation, arcdischarge, pyrolysis method, laser ablation, hydrothermal method, and solvothermal method, which can simply be classified into top-down and bottom-up approaches [15]. However, in contrast with heavymetal-based quantum dots, carbon nanoparticles are 
considered more reliable, exhibiting great advantages such as low toxicity, good water dispersibility, favorable biocompatibility, and excellent photostability especially for several clinical applications [16-17]. Furthermore, carbon nanodots derived from natural products have received great reputation due to particular merits such as photostability, excellent biocompatibility, optoelectrical properties, additional luminescence, and non-toxic nature. In addition, specific hydrophobic sites on CDs allow the improvement of diagnostics and therapy in clinical applications [18-19].

Recently, a great deal of attention have been particularly given to the production of carbon dots (CDs/CNDs) derived from natural products since they have a large number of advantages such as being renewable and sustainable and also other advantages that have already been mentioned above, [20]. Furthermore, heteroatoms from natural products promote heteroatomdoped nanocarbon dots without the addition of any external heteroatom sources. There are many ways to synthesize carbon nanodots from natural products that are incredibly green and simple compared to conventional preparation methods of carbon quantum dots from artificial carbon sources [21]. There are many literature and reports of green carbon nanodots synthesized from organic products such as from plant extracts, fruits, leaves, fruit shells and peels, algae, and fruit juice for many applications. In contrast with past applications, carbon nanodots are currently considered to be applied in photothermal treatment, drug delivery systems, photoacoustic imaging, fluorescence imaging, sensing, and magnetic resonance imaging, and is recognized to be a beneficial eco-friendly alternative to semiconductor quantum dots [22]. Yallapa et al. reported that carbon nanodots with porous particles can be synthesized from OPL (Oil Palm Leaves) which contained several important organic products such as cellulose, lignin, and hemicelluloses. Those CNDs were conjugated with fluorescent dye for cellular imaging and targeted drug delivery to cancer cells [23]. Carbon nanodots synthesized from molecules or compounds with rigid and graphene-like structures showed strong fluorescence likely due to the presence of aromatic rings and hydroxyl groups, in which the aromatic rings were able to form co-planar structures and causing the hydroxyl group to become dehydrated and introduce oxygen defects [24]. As a promising cost-effective alternative, CNDs have recently been considered as a new quantum dot candidate. In addition, carbon nanodots synthesized from aromatic rings and abundant hydroxyl groups also have benefits of better surface grafting, stable photoluminescence, good solubility, and low toxicity, and thus making them promising materials [25-27].

There are several commonly used treatment methods for cancer such as chemotherapy, radiation, surgery, targeted treatments, and immunotherapy that are applied separately or in combination [28]. However, these treatment methods might bring about various side effects [29]. On the other hand, drug nanocarriers were reported to have improved cancer treatment efficacy and diminish side effects of the conventional methods [3031]. Several studies have reported the application of CNDs on cancer treatment [32-34]. In the present study, we synthesized potential carbon nanodots (CNDs) from catechin as a natural product isolated from Uncaria gambir. The as-prepared nanoparticles (Cat-CNDs) from the organic product catechin has great biofunctions and can potentially be applied for staining specific tumor cells. The optimization of the synthesized Cat-CNDs was performed by characterizations of optical properties, spectroscopic properties, and bioassay tests using different analytical techniques. According to its unique properties discovered from the performed analysis, Cat-CNDs are highly expected to contribute to improving the method of cancer theranostics to a great extent. Furthermore, the synthesized Cat-CNDs are considered to be more biocompatible, have high cell uptake when diagnosing cancer cells, and great cell viability for staining specific tumor cells.

\section{- EXPERIMENTAL SECTION}

\section{Materials}

The dried blocks of Uncaria gambir were collected from a commercial market in Surabaya, Indonesia. Some of the chemicals such as hydrochloric acid $(97 \%, \mathrm{HCl})$, 
sodium chloride (55.5\%, $\mathrm{NaCl}$ ), ethanol (99.9\%), sodium hydroxide $(98.5 \%, \mathrm{NaOH})$, and ethyl acetate $(99.8 \%, \mathrm{EA})$ were purchased from Sigma-Aldrich, USA. The WST-8 reagent of [monosodium (2-(2-methoxy-4-nitrophenyl)3-(4-nitrophenyl)-5-(2, 4-disulfophenyl) 2H-tetrazolium)] was bought from TCl, Japan. Phosphate-buffered saline (PBS) was from UniRegion, Biotech, Taiwan. All reagents were of analytical grade and used as received without any further purification.

\section{Procedure}

\section{Isolation of catechin}

The dried blocks of Uncaria gambir (350 g) were ground into fine powders using a mortar and pestle. To attain the uniform-sized raw powders, sieving was performed at $62 \mu \mathrm{m}$ using a laboratory sieve. The fine powders were then collected for further work. The fine powders $(300 \mathrm{~g})$ were extracted with methanol for $24 \mathrm{~h}$ and then it was further extracted three more times. The methanol extract was then evaporated in order to obtain methanol crude extract. The methanol crude extract was then partitioned three times with $n$-hexane. After that, the methanol liquid extract was partitioned again three times with ethyl acetate in order to get the ethyl acetate crude extract. The ethyl acetate extract (12 g) was taken and separated by silica gel column chromatography with a gradient of $n$-hexane in EA (50:50, 40:60, 30:70, 20:80, 10:90, 0:100). The purified catechin (7 g) was isolated from solvent ratios of $n$-hexane: EA (2:8) and the structure was further confirmed by spectroscopic techniques.

\section{Synthesis of carbon nanodots (CNDs)}

The Cat-CNDs were derived from the isolated pure catechin through a single-step method of pyrolysis following a previous report [35]. Experimentally, $50 \mathrm{mg}$ of the purified catechin was powdered and placed on the isolated reactor to avoid air flow, then pyrolyzed at $250{ }^{\circ} \mathrm{C}$ for $4 \mathrm{~h}$ in a furnace for the carbonization process. The resulting Cat-CNDs were dissolved in $1 \mathrm{M} \mathrm{NaOH}$ at $60^{\circ} \mathrm{C}$, subjected to dialysis process (MWCO $10.000 \mathrm{kDa}$ ) and collected by centrifugation (12.000 rpm, $2 \mathrm{~h}$ ) for further use.

\section{Cell culture}

To culture human cervical (HeLa) tumor cells, Eagle's minimum essential medium (EMEM, containing
$1.5 \mathrm{~g} \mathrm{~L}^{-1}$ sodium bicarbonate) was used, which was added for cell medium with the respective content of $1 \%$ of antibiotic-antimycotic formulation, $1 \%$ of nonessential amino acid, $1 \%$ of 1 -glutamine, $1 \%$ of sodium pyruvate, and $10 \%$ of fetal bovine serum. The cells treated were then put safely in a humidified incubator with $5 \%$ of $\mathrm{CO}_{2}$ which was maintained at $37^{\circ} \mathrm{C}$.

\section{Confocal imaging observation}

For the exploration of the potential bioimaging and cellular distribution of Cat-CNDs, HeLa cells were implanted at a density of $5 \times 104$ cell $\mathrm{mL}^{-1}$ in $1 \mathrm{~mL}$ EMEM medium in 24-well plates. Hence, a newly medium containing varied and different concentrations of Cat-CNDs was attached to the corresponding dishes and was incubated for $1 \mathrm{~h}$. Afterwards, the medium was washed twice with PBS and fixed with ethanol. Then, the samples were captured by using a laser scanning confocal microscopy (CLSM). CLSM images were obtained by irradiating the samples with inline $\mathrm{Ar}(488 \mathrm{~nm})$ and $\mathrm{He}-$ $\mathrm{Ne}(503-680 \mathrm{~nm}$ and $588 \mathrm{~nm})$ lasers.

\section{Cytotoxicity assessment}

The assessment of cell viability was evaluated using a WST-8 assay in HeLa tumor cells. HeLa cells, which were cultured in EMEM, were cultured in 24-well plates ( 15.000 cells per well) for $24 \mathrm{~h}$. After rinsing with PBS to wash the proliferated cells and the cells were incubated with an adjusted concentration of Cat-CNDs for $24 \mathrm{~h}$. After rinsing the plate twice with PBS, WST- 8 reagent $\left(1 \mathrm{~mL}, 500 \mathrm{mg} \mathrm{mL}^{-1}\right.$ ) was supplemented and incubated for $4 \mathrm{~h}$. Afterwards, dimethyl sulfoxide $(1 \mathrm{~mL})$ was added to each well to dissolve formazan crystals, and the crystals' absorbance was determined at $570 \mathrm{~nm}$ using an Elisa reader (Biotech Powerwave XS). The greater the absorbance intensity, the more the number of live cells because more formazan was being absorbed.

Cell viability $=\frac{\text { A570 in treated cell }}{A 570 \text { in control sample }} \times 100 \%$

\section{Characterization}

The Nuclear Magnetic Resonance spectroscopy (NMR), Brucker Ultra shield Advance II $600 \mathrm{MHz}$ was used to characterize the isolated catechin compound. Related spectroscopy methods of nuclear magnetic 
resonance (NMR) such as heteronuclear single quantum coherence spectroscopy (HSQC) and heteronuclear multiple-bond coherence spectroscopy (HMBC) was also applied. Atomic force microscopic photographs were achieved using a scanning probe AFM5500M instrument (Hitachi Co., Japan) at ambient temperature. UV-Vis absorption spectra were determined using a JASCO V-670 spectrometer. By using a Rigaku $18 \mathrm{~kW}$ rotating anode source $\mathrm{X}$-ray diffractometer with $\mathrm{Cu} \mathrm{Ka} 1$ line radiation $(\lambda$ $=1.54 \AA$ ), Powder X-ray diffraction (XRD) diagrams were analyzed. By using a PerkinElmer LS 55 spectrofluorometer equipped with a $20 \mathrm{~kW}$ xenon lamp, PL spectra were measured. Fourier transforms infrared (FTIR) spectra were observed with a Nicolet AVATAR 360 FTIR instrument. Raman analysis was performed using an MRS-320 Raman Instrument system (Horiba Ltd., Japan). Colloidal stability tests were performed in different $\mathrm{pH}(3-12)$, different temperatures $\left(30-100{ }^{\circ} \mathrm{C}\right)$, and different concentrations of $\mathrm{NaCl}$ salts $(0-0.5 \mathrm{M})$. All analyses were conducted at room temperature.

\section{Statistical analysis}

The statistical study, performed by determining the cytotoxic concentration that causes a 50\% decrease in cell viability $\left(\mathrm{IC}_{50}\right.$ ), was conducted using dose-response mode on the nonlinear fitting curve in Origin software (version 8.0724, Origin Lab Inc., Northampton, MA). Means were calculated using a paired-sample t-test, and all presented data were achieved in triplicates.

\section{- RESULTS AND DISCUSSION}

\section{Extraction, Isolation, and Elucidation of Catechin}

By the extraction process, the white crystals of catechin (7 g) were obtained. High purity of this compound was determined by performing a single spot analysis at $\mathrm{R}_{\mathrm{f}}=0.39$ (eluent; Ethyl acetate: $n$-hexane $=8: 2$ ) and also determining its melting point at $125-126^{\circ} \mathrm{C}$. NMR analysis was conducted to confirm the catechin chemical structure (Fig. S1, supporting information). The analysis of the ${ }^{1} \mathrm{H}$-NMR indicated the presence of nine protons (Fig. S1) with aromatic protons that indicated chemical shifts at 5.88-6.90 ppm. Besides that, nonaromatic cyclic protons exhibited chemical shifts at 4.06$4.56 \mathrm{ppm}$. The signal that appeared at $2.53-2.98 \mathrm{ppm}$ corresponded to the secondary protons of methylene $\left(-\mathrm{CH}_{2}-\right)$. The aromatic protons appeared at $\delta_{\mathrm{H}} 6.02 \mathrm{ppm}$ $\left(\mathrm{H}_{6}, \mathrm{~d}, \mathrm{~J}=2.3 \mathrm{~Hz}\right), \delta_{\mathrm{H}} 5.88 \mathrm{ppm}\left(\mathrm{H}_{8}, \mathrm{dd}, \mathrm{J}=2.3 \mathrm{~Hz}\right), \delta \mathrm{H}$ $6.90 \mathrm{ppm}\left(\mathrm{H}_{2}, \mathrm{~d}, \mathrm{~J}=2.1 \mathrm{~Hz}\right), \delta_{\mathrm{H}} 6.8 \mathrm{ppm}\left(\mathrm{H}_{5}, \mathrm{~d}, \mathrm{~J}=6 \mathrm{~Hz}\right)$, and $\delta_{\mathrm{H}} 6.76 \mathrm{ppm}\left(\mathrm{H}_{6}, \mathrm{dd}, \mathrm{J}=6 \mathrm{~Hz}\right.$, and $\left.\mathrm{J}=2.1 \mathrm{~Hz}\right)$. According to the three coupling constant values, the $\mathrm{H}_{6}$, $\mathrm{H}_{5}$, and $\mathrm{H}_{2}$, protons formed an $\mathrm{ABX}$ system on ring $\mathrm{B}$, whereas $\mathrm{H}_{6}$ was at meta position to $\mathrm{H}_{8}$ on ring $A$. The non-aromatic cyclic protons appeared as a doublet at $\delta_{\mathrm{H}}$ $4.56 \mathrm{ppm}\left(\mathrm{H}_{2}, \mathrm{~d}\right)$ and multiplet at $\delta_{\mathrm{H}} 4.06 \mathrm{ppm}\left(\mathrm{H}_{3}, \mathrm{~m}\right)$. The last proton chemical shifts at $\delta_{\mathrm{H}} 2.53 \mathrm{ppm}\left(\mathrm{H}_{4 \mathrm{a}}, \mathrm{dd}\right)$ and $\delta_{\mathrm{H}} 2.98\left(\mathrm{H}_{4 \mathrm{~b}}, \mathrm{dd}\right)$ were given by the secondary protons of methylene $\left(-\mathrm{CH}_{2^{-}}\right)$.

The ${ }^{13} \mathrm{C}$-NMR showed 15 signals which showed the number of carbons in the structure of the isolated pure catechin compound as demonstrated in Fig. S2. Through the DEPT 135 spectrum, it could be seen that the isolated compound included seven- tertiary carbons $\left(\delta_{\mathrm{C}}, 68.30\right.$; 82.68; 95.38; 96.10; 115.19; 115.64 and $119.99 \mathrm{ppm})$, seven-quaternary carbons $\left(\delta_{\mathrm{C}}, 100.60 ; 132.13 ; 145.60\right.$; $145.70 ; 156.85 ; 157.70$ and $157.17 \mathrm{ppm})$, and onesecondary carbon $\left(\delta_{\mathrm{C}} 28.80\right)$.

The information about the correlation between directly-bonded ${ }^{1} \mathrm{H}$ on ${ }^{13} \mathrm{C}$ was obtained by the HMQC spectrum. Table 1 is the result of HMQC spectrum analysis. Moreover, the ${ }^{1} \mathrm{H}-{ }^{1} \mathrm{H}$ correlated spectroscopy (COSY) was used to analyze the correlation between proton and another proton in adjacent carbon. The correlation spectrum of ${ }^{1} \mathrm{H}-{ }^{1} \mathrm{H}$ COSY of isolated catechin compound was indicated in Fig. 1(a) and 1(b) as supplementary materials.

Moreover, the HMBC spectrum showed the presence of long-range correlations between protons and carbons that could be seen in Fig. 2(a) and 2(b) as supplementary material.

The spectrum data was made in contrast with the similar catechin compound which was isolated and identified from Acacia catechu Willdenow, reported by Acharya [36].

\section{Synthesis and Characterization of Cat-CNDs}

Pure catechin was used as raw materials to produce Cat-CNDs. The cyclohexane and benzene structure 
owned by catechin was a basic reason for choosing this organic compound. By giving a thermal treatment at $250{ }^{\circ} \mathrm{C}$, catechin will go through both dehydration and carbonization resulting in graphene like the structure of carbon dots as shown on Scheme 1. Thus, the preparation of Cat-CNDs was highlighted through a one-pot step method of pyrolysis.

To obtain solution form, the fabricated Cat-CNDs can be dissolved in polar solvents. The morphology of synthesized Cat-CNDs was firstly identified by the atomic force microscopy. The Cat-CNDs exhibited uniformly dispersible materials without any apparent aggregation. The diameter of Cat-CNDs supported its sizes between 2 and $5 \mathrm{~nm}$ (Fig. 3). The analysis of Cat-CNDs by AFM (Atomic Force Microscopy) is to assess the morphology, topography, and size distribution of the as-prepared CNDs. Fig. 3 also shows the characteristic AFM photographs of the

Table 1. ${ }^{1} \mathrm{H},{ }^{13} \mathrm{C}$ and HMBC NMR data of catechin in $\mathrm{CDCL}_{3}(\delta$ in $\mathrm{ppm})$

\begin{tabular}{lll}
\hline No. of Atom & $\delta \mathrm{H}(\mathrm{mult}, \mathrm{J} \mathrm{Hz})$ & $\delta \mathrm{c}$ \\
\hline 2 & $4.56, \mathrm{~d}$ & 82.68 \\
3 & $4.06, \mathrm{~m}$ & 68.30 \\
4 & $2.53, \mathrm{dd} ; 2.98, \mathrm{dd}$ & 28.80 \\
10 & - & 100.60 \\
5 & - & 157.17 \\
6 & $6.02(\mathrm{~d}, \mathrm{~J}=2.3 \mathrm{~Hz})$ & 96.10 \\
7 & - & 157.70 \\
8 & $5.88(\mathrm{dd}, \mathrm{J}=2.3 \mathrm{~Hz})$ & 95.38 \\
9 & - & 156.65 \\
$1^{\prime}$ & - & 132.13 \\
$2^{\prime}$ & $6.90(\mathrm{~d}, \mathrm{~J}=2.1 \mathrm{~Hz})$ & 115.19 \\
$3^{\prime}$ & - & 145.60 \\
$4^{\prime}$ & - & 147.70 \\
$5^{\prime}$ & $6.8(\mathrm{~d}, \mathrm{~J}=6 \mathrm{~Hz})$ & 115.64 \\
$6^{\prime}$ & $6.76(\mathrm{dd} 6.76(\mathrm{dd}, \mathrm{J}=6,82.1 \mathrm{~Hz})$ & 119.99 \\
\hline
\end{tabular}

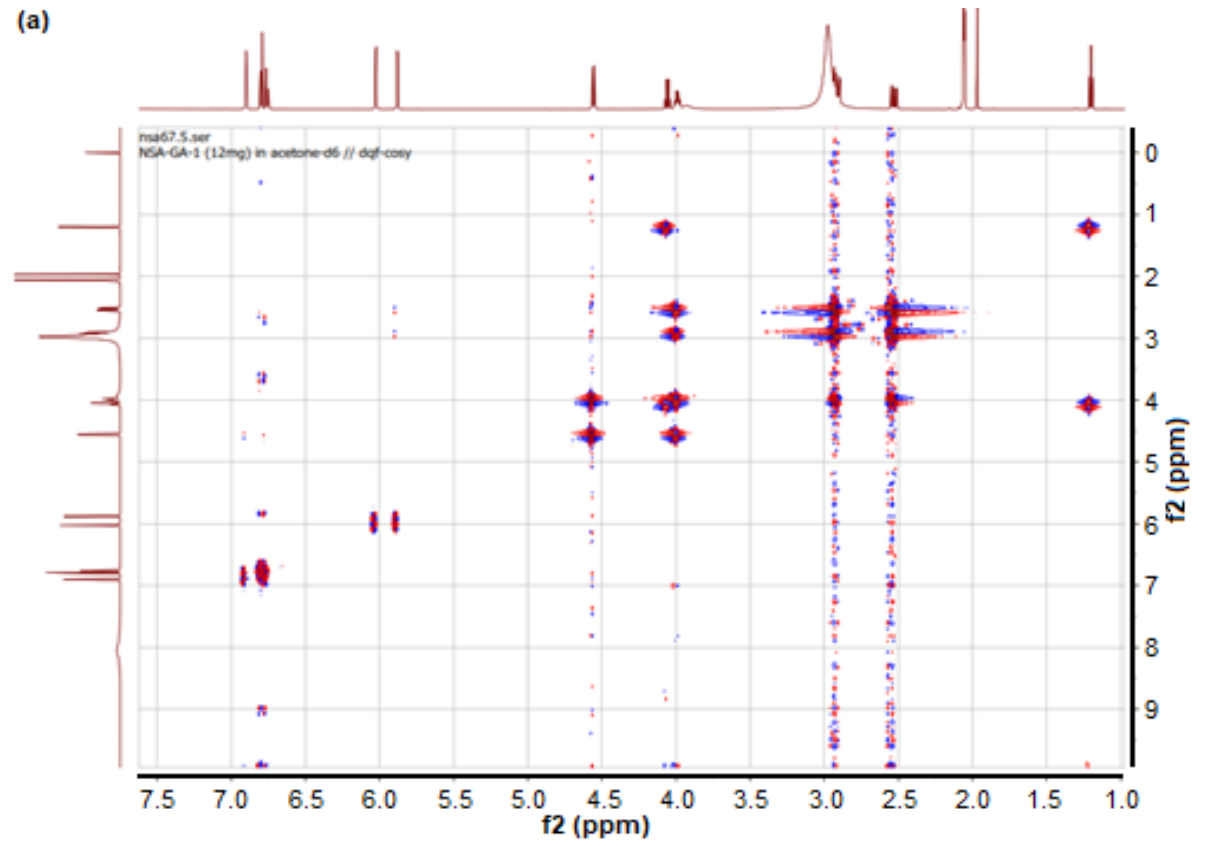

(b)

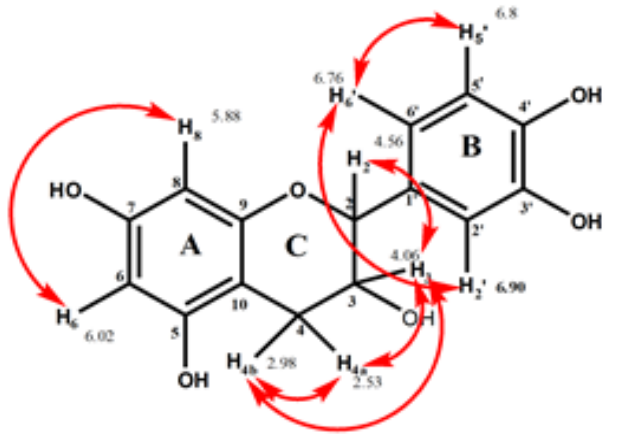

Fig 1. (a) The ${ }^{1} \mathrm{H}-{ }^{1} \mathrm{H}$ correlation spectrum of catechin, (b) The correlation of ${ }^{1} \mathrm{H}-{ }^{1} \mathrm{H}$ COSY of isolated compound 


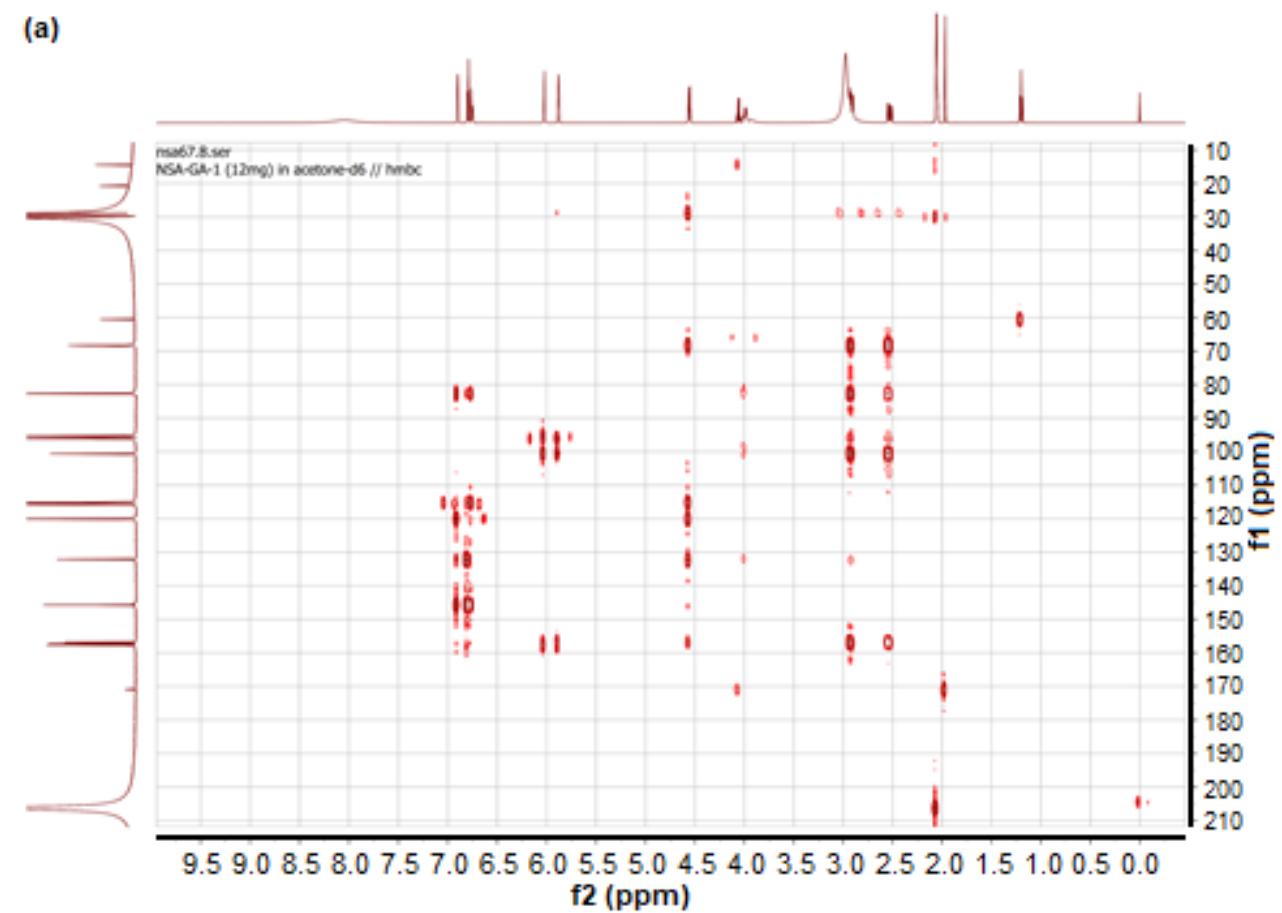

(b)

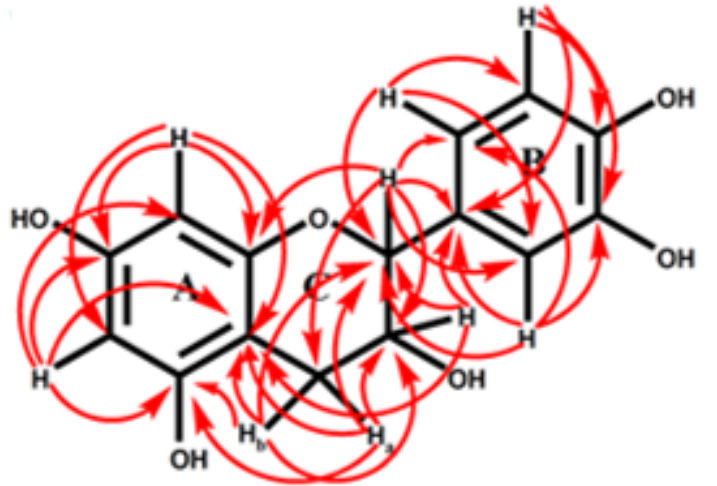

Fig 2. (a) The long-range correlation spectrum of ${ }^{1} \mathrm{H}-{ }^{13} \mathrm{C}$ HMBC of isolated catechin compound, (b) The correlation of $\mathrm{HMBC}$ in the isolated catechin compound

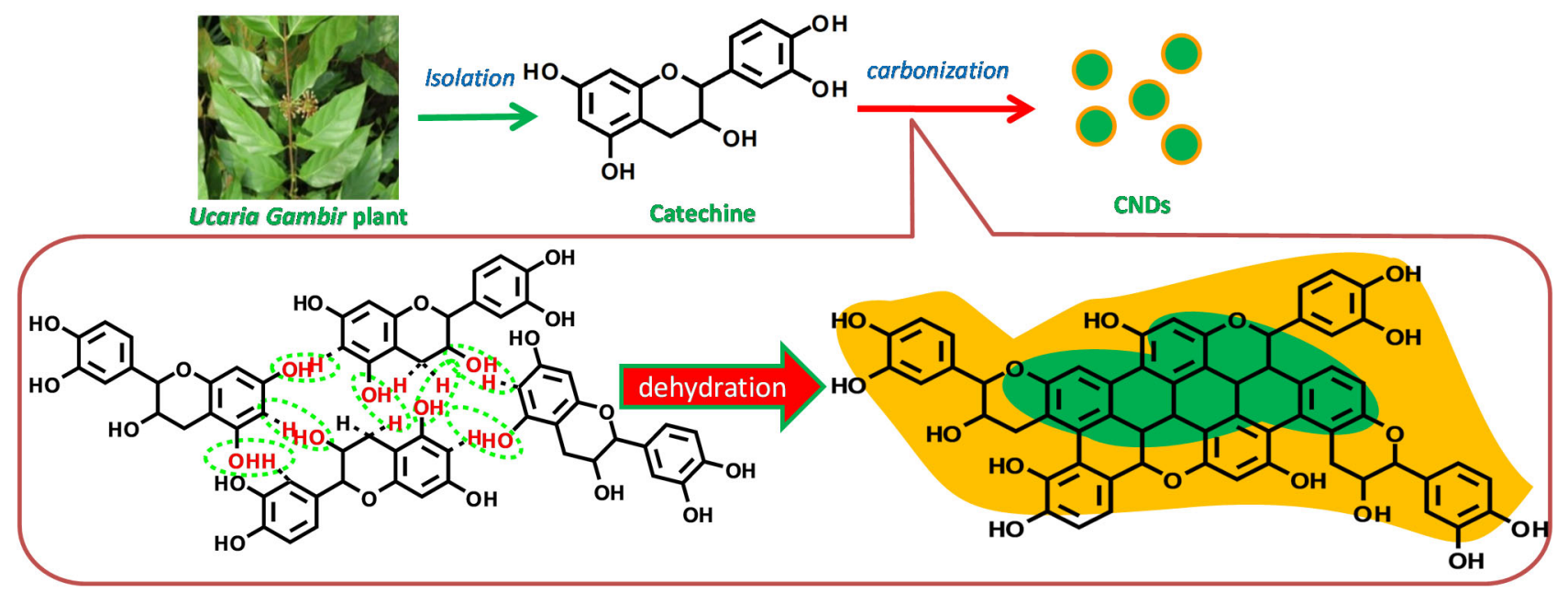

Scheme 1. Schematic illustration synthesis of Cat-CNDs from catechin 
(a)

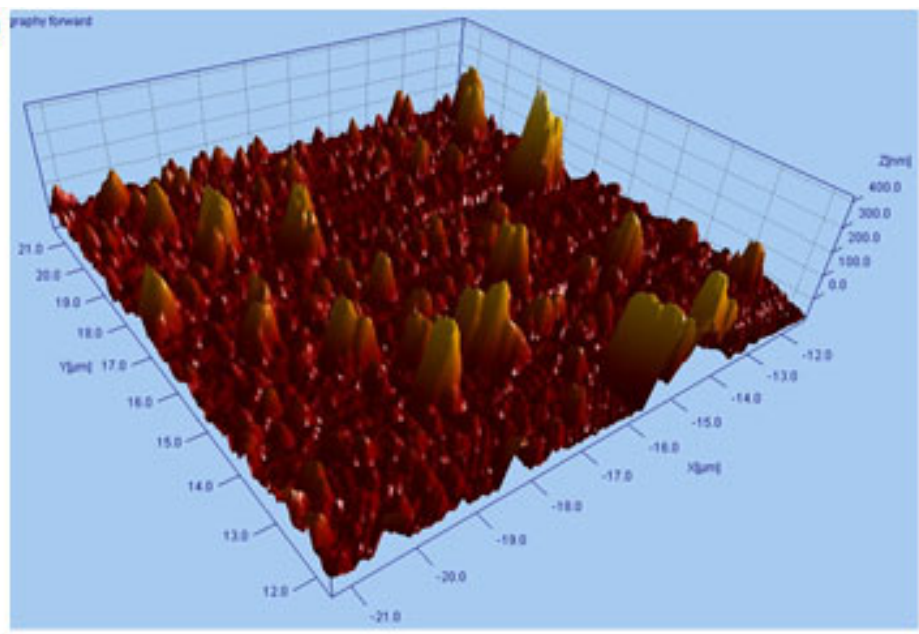

(b)

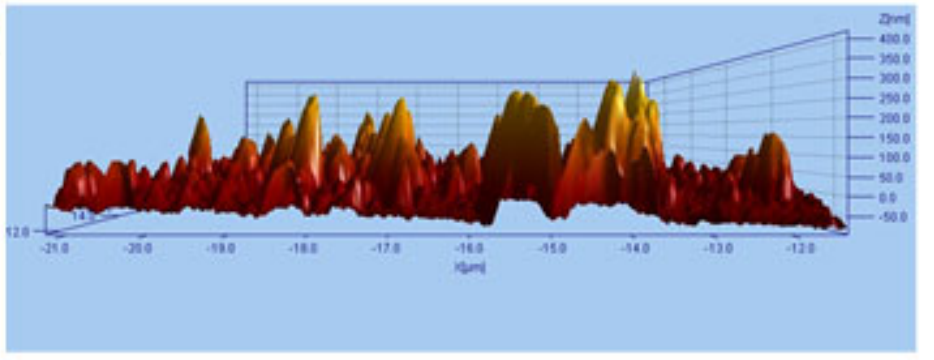

(c)

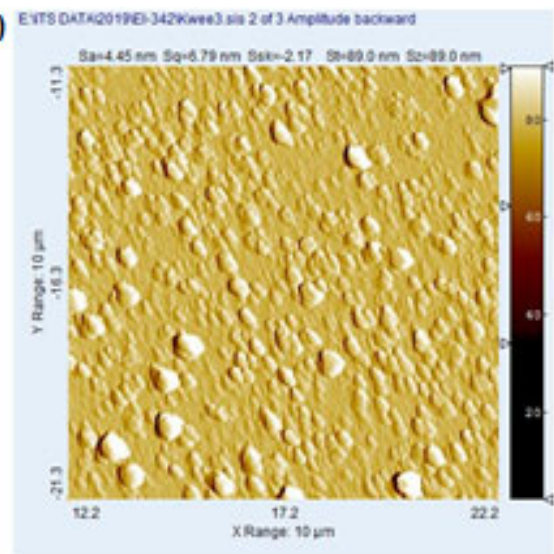

(d)

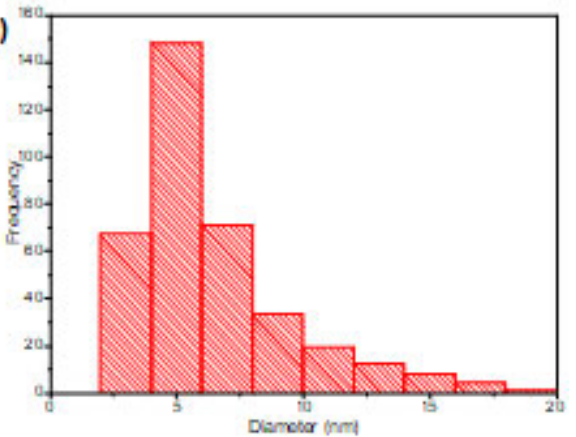

Fig 3. AFM photographs of Cat-CNDs on diagonal (a); vertical (b); top views (c); and its histogram (d)

as-synthesized CNDs solution. The height profile indicated that even though some particles had a size diameter of about $100 \mathrm{~nm}$, the average size of these nanoparticles were about $5 \mathrm{~nm}$ supported by the histogram of the Cat-CNDs interpreted by the Image J software (Fig. 3(c)). Furthermore, it was revealed that the Cat-CNDs were well dispersed in the appropriate solvent and appeared in the spherical shape. The diameter of the CNDs was included in its size range which has been widely developed, which measures less than $10 \mathrm{~nm}$ in size [37].

Crystal characterization of the synthesized CatCNDs was investigated by XRD (Fig. 4). Its crystallinity was confirmed by a definite peak observed in the range of the shoulder diffractogram between 5 and $30^{\circ}$, confirming the peak of graphite carbon structure (based on crystal database JCPDS 74-2328). The XRD data also demonstrated interlayer spacing of Cat-CNDs on (003) plane at $11.15 \AA$. The pyrolyzed CNDs performed weak XRD intensity, indicating nano-sized materials that matched with the supporting literature on nanostructure graphitic nature [38-39]. The average size of the crystalline CNDs with a $2 \theta$ position of 15.88 (FWHM = $7.2804^{\circ}$ ) was calculated to be $0.2 \mathrm{~nm}$ according to the Scherrer's equation.

Further observation focused on photo-physical properties of the CNDs that was acquired by using UVVis spectroscopy (Fig. 5(a)). The spectrum of pure catechin solution showed two absorption peaks that were

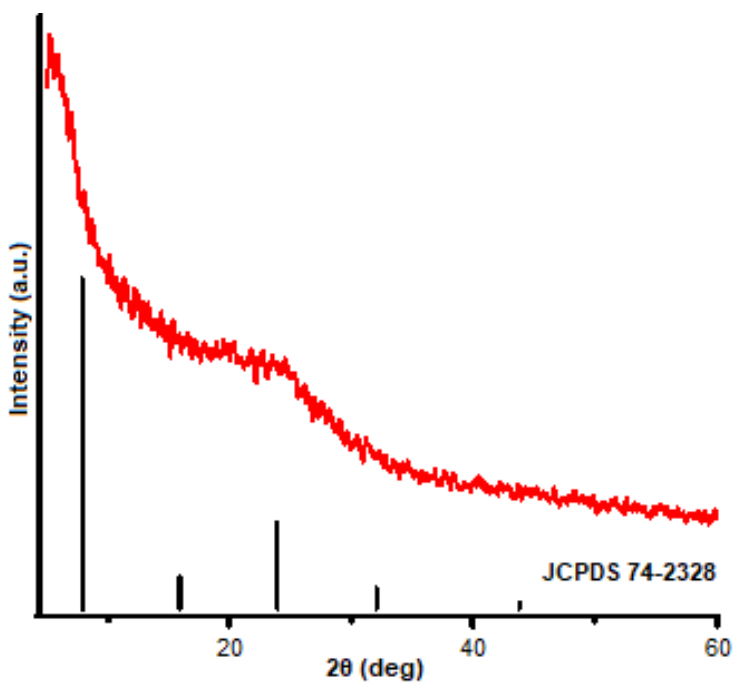

Fig 4. XRD pattern of Cat-CNDs 
found at wavelengths of 267 and $318 \mathrm{~nm}$ corresponding to $\pi-\pi^{*}$ transitions of the aromatic ring. After the pyrolysis process, the synthesized Cat-CNDs possessed a nearly similar absorption spectrum to catechin. Furthermore, it was noticeable that two absorption peaks of Cat-CNDs appeared at around $267 \mathrm{~nm}$, which was assigned to $\pi-\pi^{*}$, and $500 \mathrm{~nm}$ (blue shift emission) influencing electrostatic interactions between the aromatic rings within the catechin compound. The optical analysis of the as-prepared CNDs compared with bare catechin was further investigated (Fig. 5(b)). The data showed a strong fluorescent intensity presented as a broad peak (PL) at $500 \mathrm{~nm}$, whereas pure catechin solution relatively exhibited a very weak fluorescent intensity centered at around $480 \mathrm{~nm}$ when both of the samples were exposed with excited wavelength at $380 \mathrm{~nm}$ (supported by the photograph in Fig. 5(b)). The photograph figures also show that Cat-CNDs had good solubility in water and hence having stronger fluorescence. For this reason, it was favorable for this material to be used as a staining agent for targeting tumor cells. Furthermore, it was noticed that the CatCNDs held excitation-dependent fluorescence on the complexity of the excited states of the CNDs, affecting the bandgap on the surface state of the carbon nanodots material [40].

Fig. 5(c) shows the Raman peak detected at $1590 \mathrm{~cm}^{-1}$ referring to a typical $\mathrm{G}$ band to the graphene $\left(\mathrm{sp}^{2}\right)$, due to the action of a double degenerated photo mode integrated with the symmetric $\mathrm{E}_{2 \mathrm{~g}}$ in graphitic nature and the vibrations of the $\mathrm{sp}^{2}$ were determined by the bonded carbon atoms in the two-dimension system of a hexagonal lattice [23]. The Raman data in Fig. 5(c) also show a peak at $1335 \mathrm{~cm}^{-1}$ described as the $\mathrm{D}$ band due to the disorder-induced nature in graphite of the $\mathrm{sp}^{3}$ hybridization among carbon atoms which was inferred
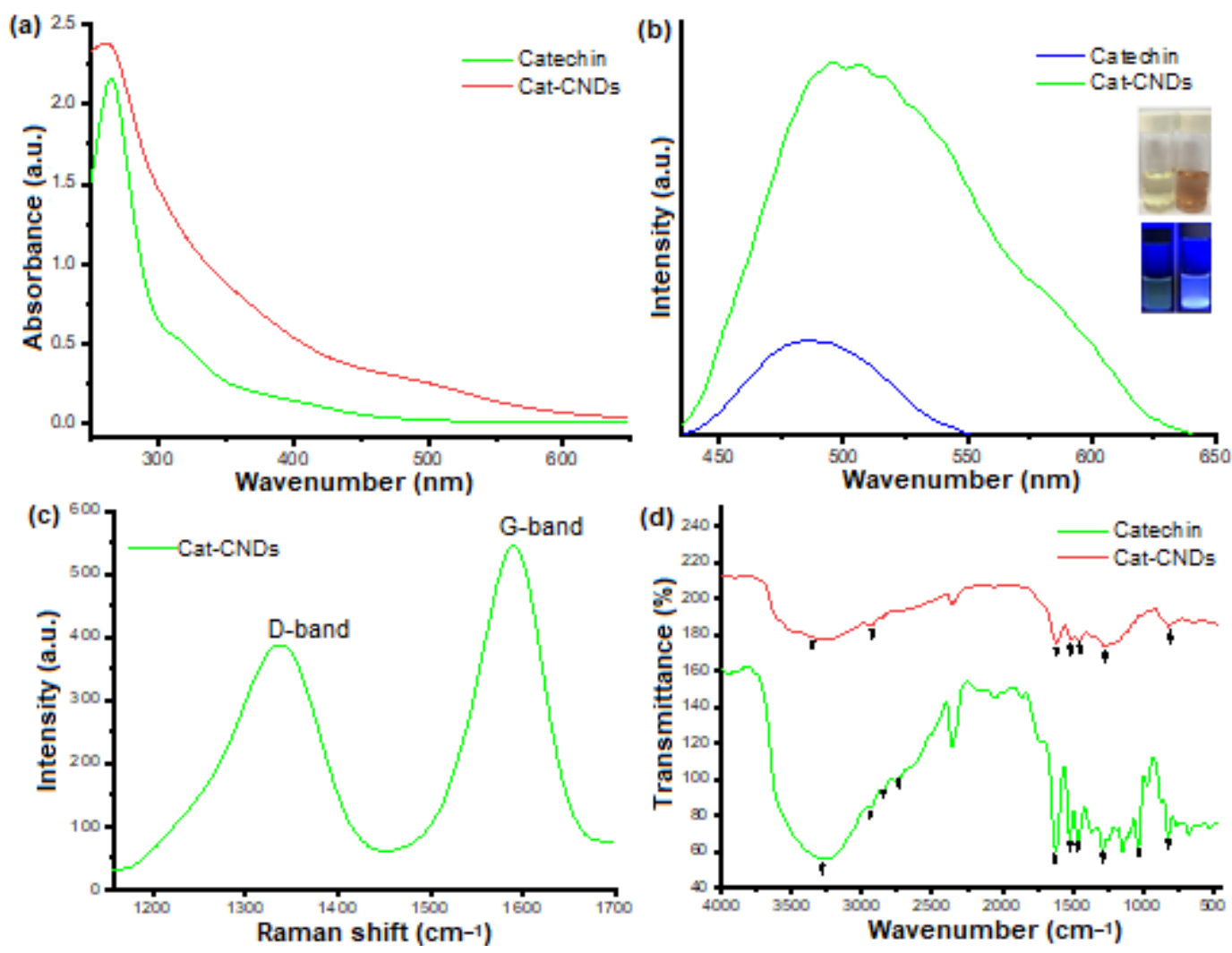

Fig 5. UV-Vis spectra of catechin (green solid line) and Cat-CNDs (red solid line) (a). PL spectra of catechin (blue solid line) and Cat-CNDs (red solid line). Inset: photographs of catechin and Cat-CNDs solutions under visible light and UV light (b). Raman spectra of Cat-CNDs (c). FTIR spectra of Cat-CNDs (red solid line) compared with bare Catechin (green solid line) (d) 
to the $A_{1 g}$ mode [23]. These two bands are common bands of graphene or graphene oxide structure thus confirming the formation of a graphene oxide-like structure on the prepared Cat-CNDs. The calculation of the different intensity ratio of the $D$ to $G$ bands $\left(I_{D} / I_{G}\right)$ resulted the value of 0.84 , indicating the purity of graphitic formation. The CNDs sample with amorphous nature had a high ID/IG ratio whereas the CNDs sample with a high degree of graphitization was indicated by a relatively lower $\mathrm{I}_{\mathrm{D}} / \mathrm{I}_{\mathrm{G}}$ ratio [41]. This means that the lower the intensity ratio of $\mathrm{I}_{\mathrm{D}} / \mathrm{I}_{\mathrm{G}}$, the more purified graphitic crystals were dominated. Therefore, the Raman spectrum confirmed a high purity of crystalline graphite in the carbon nanodots obtained from catechin.

As shown in Fig. 5(d), the functional groups of the Cat-CNDs were systemically analyzed with infra-red spectroscopy and compared with bare catechin.

For the catechin compound, a strong peak showed the stretching frequency of $\mathrm{O}-\mathrm{H}$ bands at $3319 \mathrm{~cm}^{-1}$, while $\mathrm{C}-\mathrm{H}$ stretching of $\mathrm{sp}^{2}$ hybridization was found at $2930 \mathrm{~cm}^{-1}$, and $\mathrm{C}-\mathrm{H}$ asymmetric and symmetric stretching vibrations of methane $\left(-\mathrm{CH}_{2-}\right)$ at 2871 and $2835 \mathrm{~cm}^{-1}$, respectively. Furthermore, the bands between 1624 and $1525 \mathrm{~cm}^{-1}$ corresponded to the $\mathrm{C}=\mathrm{C}$ stretching of the aromatic ring, while $\mathrm{C}-\mathrm{O} / \mathrm{C}-\mathrm{O}-\mathrm{C}$ stretching vibrations were found at $1285 \mathrm{~cm}^{-1}$ (symmetric band) and $1139 \mathrm{~cm}^{-1}$ (symmetric band), and $\mathrm{C}-\mathrm{H}$ bending of $\mathrm{CH}_{2}$ (out of plane) was found at $813 \mathrm{~cm}^{-1}$ [41]. In contrast the spectra for Cat-CNDs showed a broad peak at $3280 \mathrm{~cm}^{-1}$ that was attributed to the stretching vibration of a small number of residual hydroxyl groups that remained even after dehydrogenation, while the peak at $2926 \mathrm{~cm}^{-1}$ corresponded to $\mathrm{C}-\mathrm{H}$ stretching vibration and aromatic ring stretching of the $\mathrm{C}=\mathrm{C}$ vibration appeared at 1602 , 1503 , and $1450 \mathrm{~cm}^{-1}$. The $\mathrm{C}-\mathrm{O}-\mathrm{C}$ stretching vibration was observed at $1280 \mathrm{~cm}^{-1}$, and the broad peak at $810 \mathrm{~cm}^{-1}$ was attributed to the $\mathrm{C}=\mathrm{C}-\mathrm{H}$ out-of-plane bending. The synthesized carbon dots showed favorable hydrophilicity and good dispersion in water due to the polar functional groups on the surface site.

\section{Stability Evaluation of Cat-CNDs}

The colloidal stability analysis was carried out to assure the stability of Cat-CNDs. The stability of nanoparticles in aqueous solutions is vital for both biomedical and clinical uses. The first observation to study the pH effect on the CNDs, as shown in Fig. 6. The result showed that Cat-CNDs solution at $\mathrm{pH} 5$ to 11 showed good stability up to $24 \mathrm{~h}$ after $\mathrm{pH}$ adjustment. However, Cat-CNDs at $\mathrm{pH} 3$ and 4 showed precipitated particulates for the first $6 \mathrm{~h}$. The change in appearance of the Cat-CNDs was observed at $\mathrm{pH} 12$, where its color became bright brown. These conditions were likely due to the destruction of Cat-CNDs in extreme conditions. At low $\mathrm{pH}$, the hydroxyl-abundant environment most likely caused the increase of hydrogen bonding of the CNDs [43], whereas structural destruction occurred when the CNDs were treated in high $\mathrm{pH}$ resulting in the color change. These findings were supported by UV-Vis spectra analysis (Fig. 6(b)), where $\pi^{*}-\pi$ excitation of CNDs at wavelength below $300 \mathrm{~nm}$ was disrupted by its electrostatic effect.

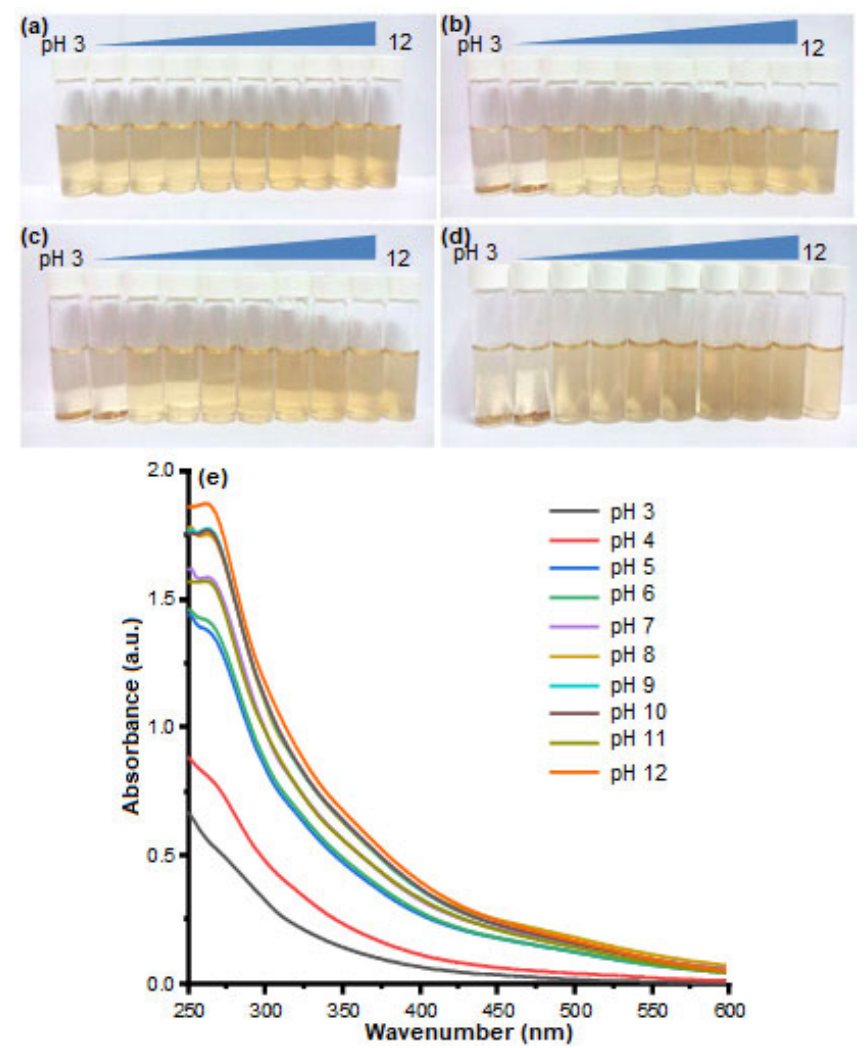

Fig 6. Photograph images of Cat-CNDs from $\mathrm{pH} 3$ to $\mathrm{pH}$ 12 at (a) $0 \mathrm{~h}$, (b) $6 \mathrm{~h}$, (c) $12 \mathrm{~h}$, and (d) $24 \mathrm{~h}$. (e) The UVVis Spectra of Cat-CNDs from $\mathrm{pH} 3$ to $\mathrm{pH} 12$ 
The stability of CNDs was then observed against varied thermal treatment $\left(30-100^{\circ} \mathrm{C}\right)$. As a result, in Fig. $7(\mathrm{a})$, there were no coagulation and color change, while UV-Vis spectroscopy analysis revealed that all of the varied CNDs resulted similar absorption spectra. The synthesis of Cat-CNDs that reached up to $270{ }^{\circ} \mathrm{C}$ produced good thermal stability of this material and fulfilled the thermal stability requirement for materials that can be applied for the human body.

Further assessment was focused on Cat-CNDs stability on varied ionic strength by $\mathrm{NaCl}$ addition. This part was considered necessary due to the blood circulation in the human body that is affected by salt concentration. Thus, the effect of ionic strength on prepared Cat-CNDs was a crucial factor for further clinical applications. As shown in Fig. 8(a), the CNDs mixed with varying concentrations of $\mathrm{NaCl}$ salts (from 0.1 to $0.5 \mathrm{M}$ ) show similar conditions with the untreated Cat-CNDs, showing no coagulated solids even until $24 \mathrm{~h}$.

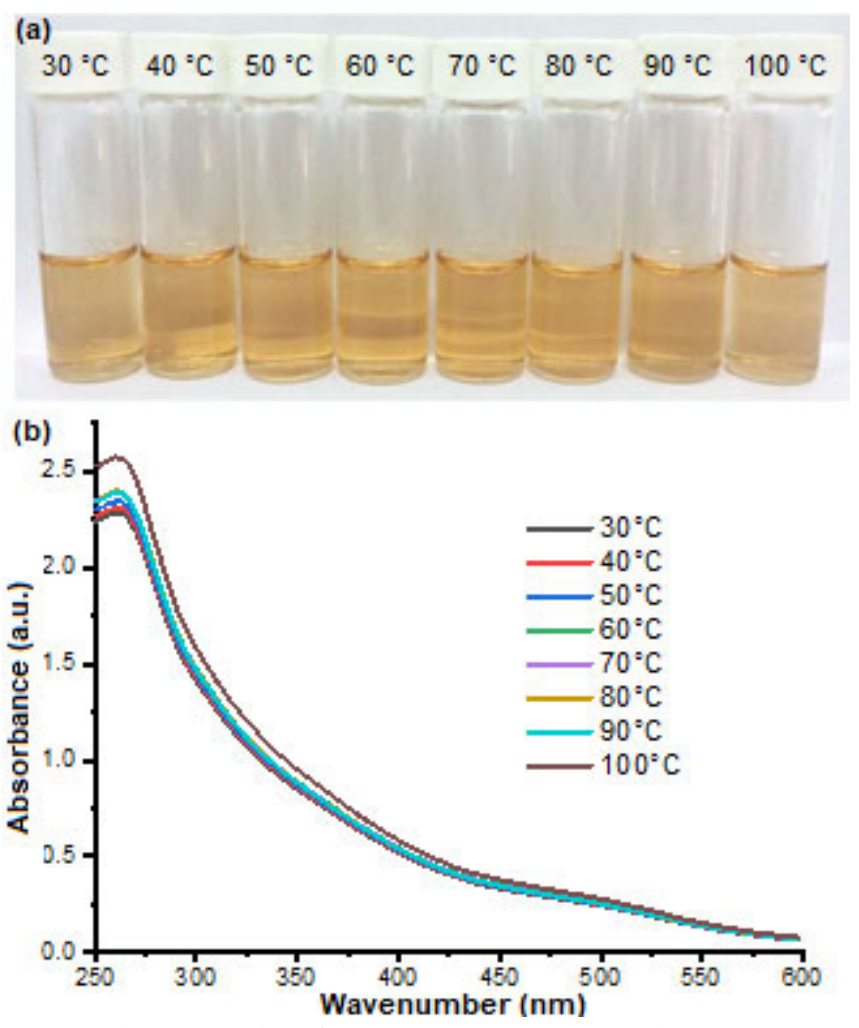

Fig 7. Photograph of Cat-CNDs on varied temperature assessment at $30,40,50,60,70,80,90$, and $100^{\circ} \mathrm{C}$ (a), The $\mathrm{UV}-\mathrm{V}$ is spectra of Cat-CNDs at varied temperatures treatment after $24 \mathrm{~h}(\mathrm{~b})$
This data is supported by the UV-Vis spectra (Fig. $8(\mathrm{e})$ ), where the maximum wavelengths of the treated CNDs were similar to the untreated Cat-CNDs. Therefore, all these stability investigations prove the potential of this material for bio-applications and other fields of commercial purpose.

\section{Confocal Observation}

The fluorescence properties possessed by CatCNDs were the main factor to consider applying this material for tumor cell staining. Laser confocal scanning microscopy (LCSM) was used to improve the fluorescent properties as well as the cellular uptake and internalization of Cat-CNDs on the HeLa tumor cell. After $4 \mathrm{~h}$ of addition and incubation of Cat-CNDs onto HeLa (Fig. 9), its green emission was detected and localized in the cytoplasm of Hela tumor cells. This finding

(a)

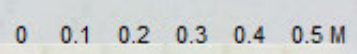

(b)

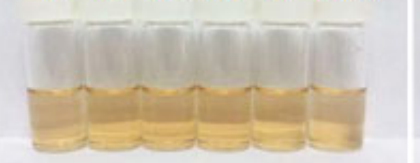

(c)

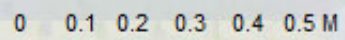

(d)

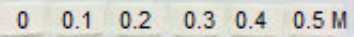

$\begin{array}{llllll}0 & 0.1 & 0.2 & 0.3 & 0.4 & 0.5 \mathrm{M}\end{array}$

0.40 .511
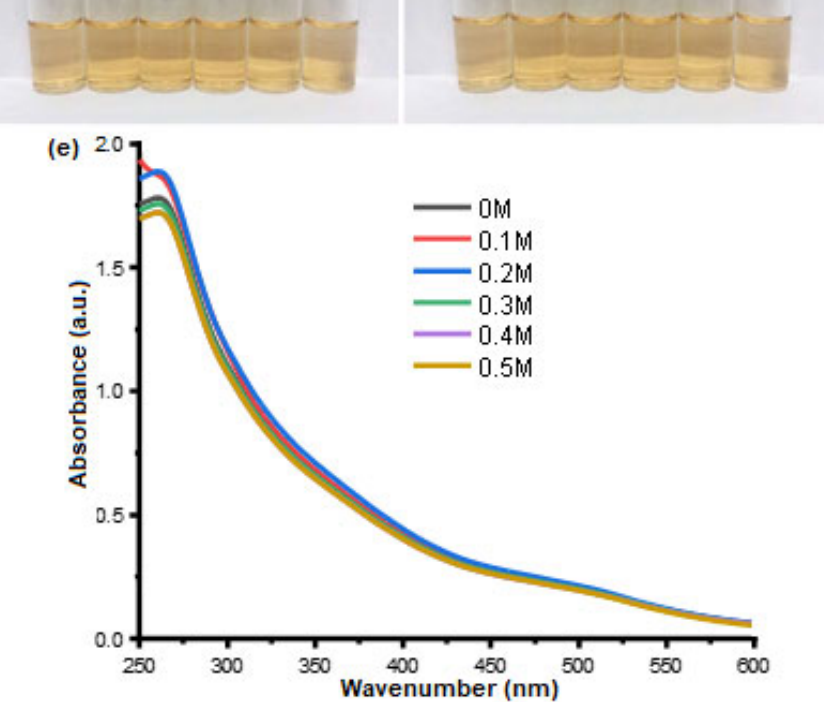

Fig 8. Photograph images of Cat-CNDs on varied $\mathrm{NaCl}$

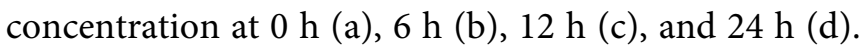
The UV-Vis spectra of Cat-CNDs at varied concentrations of $\mathrm{NaCl}$ after $24 \mathrm{~h}(\mathrm{e})$ 
indicates that CNDs were successfully taken up by the cells.

The facile internalization of CNDs on the tumor cell was considered based on the basic properties of the catechin compound that possess high affinities to a variety of proteins expressed on the cell membrane by massive hydrogen bonding [44-45]. Further reports also stated that the insertion of catechin was founded by an association of membrane plasma by lipid rafts [46]. We speculate to that those reasons made the Cat-CNDs significantly appear on the cytoplasm. To ensure the position of Cat-CNDs on the cytoplasm, the Z stacking mode of CLSM was used (Fig. $10)$, where higher emission of the cell was found in the middle position. Therefore, these findings proved the potential and biocompatibility of Cat-CNDs while staining on a specific tumor cell and showed similar results with a previous report [46].

\section{Cytotoxicity Test with CCK-8 Assay}

Several studies have reported the anticancer potential of catechin derivatives, including the cytotoxicity of catechin when it is modified to nanoparticle form, which is an important aspect to verify its biocompatibility in biomedical and pharmaceutical applications. The cytotoxicity evaluation is conducted by
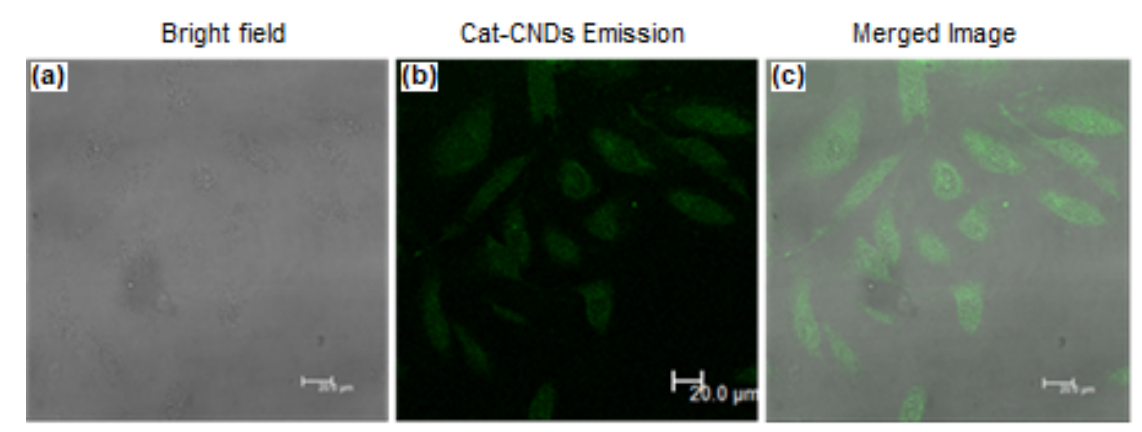

Fig 9. CLSM images of HeLa tumor cell after $4 \mathrm{~h}$ incubation with Cat-CNDs
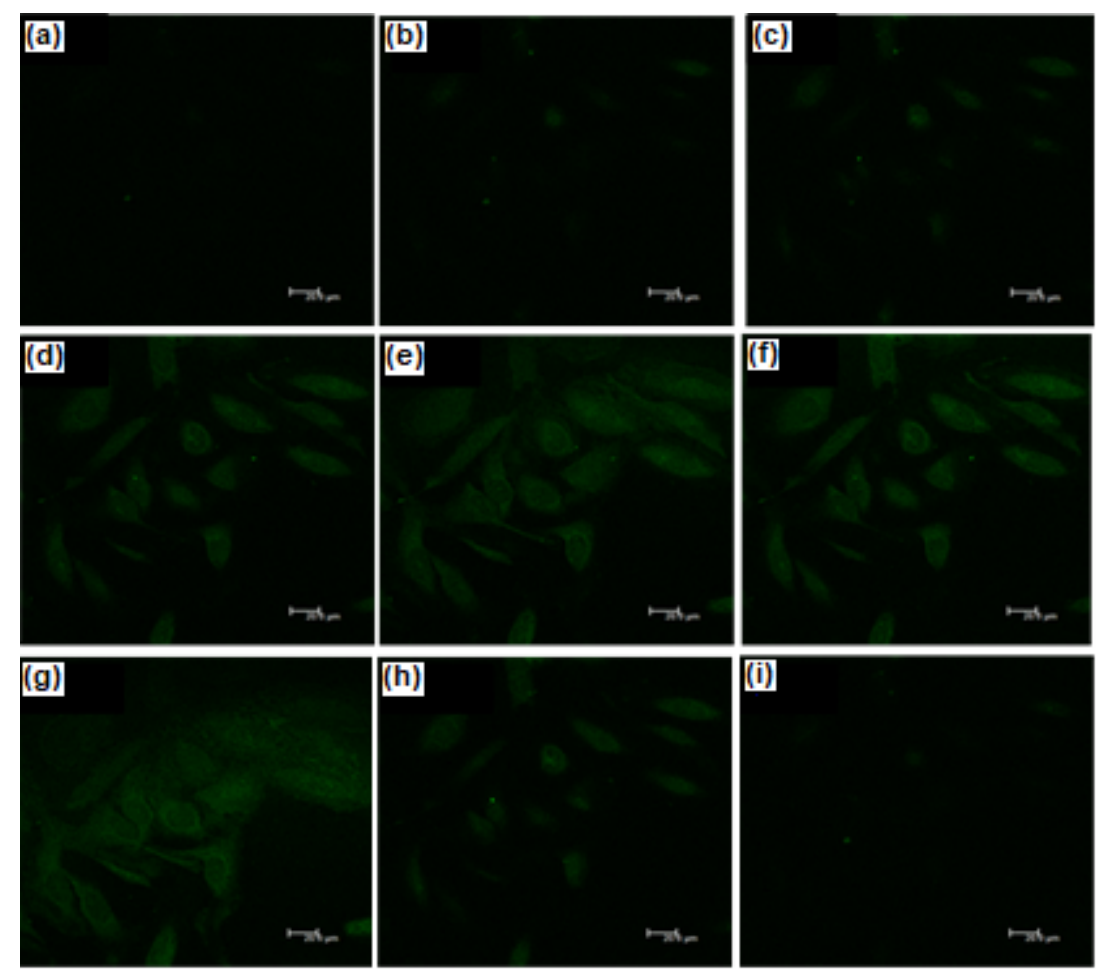

Fig 10. CLSM images of HeLa cells through z-stacking mode after $4 \mathrm{~h}$ treated with Cat-CNDs (a-i) Hela cells images captured by excitation at $488 \mathrm{~nm}$ 


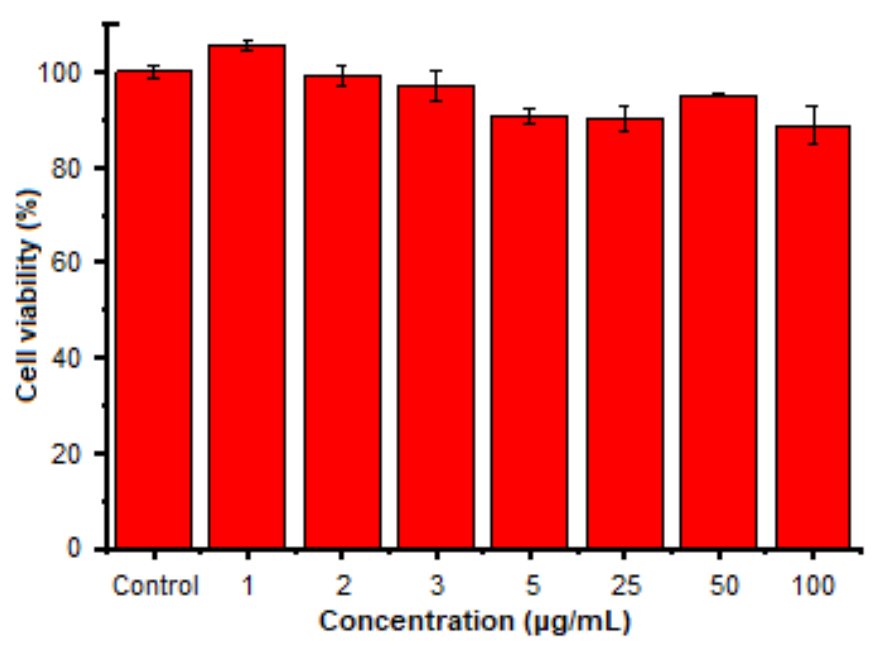

Fig 11. Cell viability assessed byWST-8 assay of Hela Cells after $24 \mathrm{~h}$ of treatment with Cat-CNDs. WST-8 data is shown as means \pm SD with $n=3$

incubating the adjusted concentration of Cat-CNDs on HeLa cells via WST-8 assay (Fig. 11). After being incubated for $24 \mathrm{~h}$, the cell viability results showed that the cell had a high viability percentage of over $80 \%$ in concentrations of up to $400 \mu \mathrm{g} \mathrm{mL}^{-1}$ and $\mathrm{IC}_{50}$ of about $1815 \mu \mathrm{g} \mathrm{mL} \mathrm{mL}^{-1}$. This strongly indicated that Cat-CNDs have very low toxicity. Previous reports show that synthesized carbon nanodots are classified into non-toxic and low toxic categories if the percentage of cell viability is between $50.0-80.0 \%$ [47-48].

\section{- CONCLUSION}

Catechin was successfully isolated from Uncaria gambir as raw material for the synthesis of Cat-CNDs through a single-step pyrolysis method and was later used for staining specific tumor cells. The resulting Cat-CNDs possess excellent optical properties. The average size of the Cat-CNDs was found to be below $5 \mathrm{~nm}$ with nearspherical shape and was crystalline in nature, which was confirmed by the analysis of the physicochemical properties. Moreover, the Cat-CNDs could be easily internalized into the tested Hela cancer cells and demonstrated excellent biocompatibility without any obvious toxicity. Due to their good biocompatibility, nontoxicity, strong photoluminescence, and eco-friendliness; this work strongly suggested that the as-synthesized CatCNDs have much potential to be applied for various biomedical applications specifically in targeted staining of specific tumor cells.

\section{- ACKNOWLEDGMENTS}

Authors would like to thank Universitas Airlangga, Indonesia for research facilities and funding under contract 341/UN3.14/LT/2019.

\section{- REFERENCES}

[1] Nandika, D., Syamsu, K., Arinana, A., Kusumawardani, D.T., and Fitriana, Y., 2019, Bioactivities of catechin from Gambir (Uncaria gambir Roxb.) against wood-decaying fungi, BioResources, 14 (3), 5646-5656.

[2] Davis, A.P., and Figueiredo, E., 2007, A checklist of the Rubiaceae (coffee family) of Bioko and Annobon (Equatorial Guinea, Gulf of Guinea), Syst. Biodivers., 5 (2), 159-186.

[3] Anggraini, T., Tai, A., Yoshino, T., and Itani, T., 2011, Antioxidative activity and catechin content of four kinds of Uncaria gambir extract from West Sumatra, Indonesia, Afr. J. Biochem. Res., 5 (1), 3338.

[4] Amir, M., Mujeeb, M., Khan, A., Ashraf, K., Sharma, D., and Aqil, M., 2012, Phytochemical analysis and in vitro antioxidant activity of Uncariagambir, Int. J. Green Pharm., 6 (1), 67-72.

[5] Ahmad, R., Hashim, H.M., Noor, Z.M., Ismail, N.H., Salim, F., Lajis, N.H., and Shaari, K., 2011, The Antioxidant and antidiabetic potential activity of Malaysian Uncaria, Res. J. Med. Plant, 5 (5), 587-595.

[6] Picking, D., Delgoda, R., Boulogne, I., and Mitchell, S., 2013, Hyptis verticillata Jacq: A review of its traditional uses extension, phytochemistry, pharmacology, and toxicology, J. Ethnopharmacol., 147 (1), 16-41.

[7] Heitzman, M.E., Neto, C.C., Winiarz, E.,Vaisberg, A.J., and Hammond, G.B., 2005, Ethnobotany, phytochemistry, and pharmacology of Uncaria (Rubiaceae), Phytochemistry, 66 (1), 5-29.

[8] Gadkari, P.V., and Balaraman, M., 2015, Catechins: Sources, extraction, and encapsulation: A review, Food Bioprod. Process., 93, 122-138. 
[9] Zhang, Q., Zhao, J.J., Xu, J., Feng, F., and Qu, W., 2015, Medicinal uses, phytochemistry and pharmacology of the genus Uncaria gambir, J. Ethnopharmacol., 173, 48-80.

[10] Melia, S., Novia, D., and Juliyarsi, I., 2015, Antioxidant and antimicrobial activities of gambir (Uncaria gambir Roxb) extracts and their application in rendang, Pak. J. Nutr., 14 (12), 938-941.

[11] Ferdinal, N., 2014, A simple purification method of catechin from gambier, IJASEIT, 4 (6), 53-55.

[12] Fujiwara, H., Takayama, S., Iwasaki, K., Tabuchi, M., Yamaguchi, T., Sekiguchi, K., Ikarashi, Y., Kudo, Y., Kase, Y., Arai, H., and Yaegashi, N., 2011, Yokukansan, a traditional Japanese medicine, ameliorates memory disturbance and abnormal social interaction with anti-aggregation effect of cerebral amyloid $\beta$ proteins in amyloid precursor protein transgenic mice, Neuroscience, 180, 305-313.

[13] Mizukami, K., Asada, T., Kinoshita, T., Tanaka, K., Sonohara, K., Nakai, R., Yamaguchi, K., Hanyu, H., Kanaya, K., Takao, T., Okada, M., Kudo, S., Kotoku, H., Iwakiri, M., Kurita, H., Miyamura, T., Kawasaki, Y., Omori, K., Shiozaki, K., Odawara, T., Suzuki, T., Yamada, S., Nakamura, Y., and Toba, K., 2009, A randomized cross-over study of a traditional Japanese medicine (kampo), yokukansan, in the treatment of the behavioural and psychological symptoms of dementia, Int. J. Neuropsycho. Pharmacol., 12 (2), 191-199.

[14] Shen, J., Zhu, Y., Yang, X., and Li, C., 2012, Graphene quantum dots: Emergent nanolights for bioimaging, sensors, catalysis, and photovoltaic devices, Chem. Commun., 48 (31), 3686-3699.

[15] Wang, X., Cao, L., Yang, S.T., Lu, F., Meziani, M.J., Tian, L., Sun, K.W., Bloodgood, M.A., and Sun, Y.P., 2010, Bandgap-like strong fluorescence in functionalized carbon nanoparticles, Angew. Chem. Int. Ed., 49, 5310-5314.

[16] Sun, Y.P., Wang, X., Lu, F., Cao, L., Meziani, M.J., Luo, P.G., Gu, L., and Veca, L.M., 2008, Doped carbon nanoparticles as a new platform for highly photoluminescent dots, J. Phys. Chem. C, 112 (47), 18295-18298.
[17] Vandarkuzhali, S.A., Jeyalakshmi, V., Sivaraman, G., Singaravadivel, S., Krishnamurthy, K.R., and Viswanathan, B., 2017, Highly fluorescent carbon dots from pseudo-stem of banana plant: Applications as nanosensor and bio-imaging agents, Sens. Actuators, B, 252, 894-900.

[18] Namdari, P., Negahdari, B., and Eatemadi, A., 2017, Synthesis, properties and biomedical applications of carbon-based quantum dots: An updated review, Biomed. Pharmacother., 87, 209-222.

[19] Zhang, Q., Xie, S., Yang, Y., Wu, Y., Wang, X., Wu, J., Zhang, L., Chen, J., and Wang, Y., 2018, A facile synthesis of highly nitrogen-doped carbon dots for imaging and detection in biological samples, $J$. Anal. Methods Chem., 2018, 7890937.

[20] Himaja, A.L., Karthik, P.S., Sreedhar, B., and Singh, S.P., 2014, Synthesis of carbon dots from kitchen waste: Conversion of waste to value added product, J. Fluoresc., 24 (6), 1767-1773.

[21] Das, R., Bandyopadhyay, R., and Pramanik, P., 2018, Carbon quantum dots from natural resource: A review, Mater. Today Chem., 8, 96-109.

[22] Baguley, D.M., Humphriss, R.L., Axon, P.R., and Moffat, D.A., 2005, Change in tinnitus handicap after translabyrinthine vestibular schwannoma excision, Otol. Neurotol., 26 (5), 1061-1063.

[23] Yallappa, S., Manaf, S.A.A., and Hegde, G., 2018, Synthesis of a biocompatible nanoporous carbon and its conjugation with florescent dye for cellular imaging and targeted drug delivery to cancer cells, New Carbon Mater., 33 (2), 162-172.

[24] Wang, J., Cheng, C., Huang, Y., Zheng, B., Yuan, H., Bo, L., Zheng, M.W., Yang, S.Y., Guo, Y., and Xiao, D., 2014, A facile large-scale microwave synthesis of highly fluorescent carbon dots from benzenediol isomers, J. Mater. Chem. C, 2 (25), 5028-5035.

[25] Xiao, F.X., Miao, J., and Liu, B., 2014, Layer-bylayer self-assembly of CdS quantum dots/graphene nanosheets hybrid films for photoelectrochemical and photocatalytic applications, J. Am. Chem. Soc., 136 (4), 1559-1569.

[26] Fahmi, M.Z., Sukmayani, W., Khairunisa, S.Q., Witaningrum, A.M., Indriati, D.W., Matondang, 
M.Q.Y., Chang, J.Y., Kotaki, T., and Kameoka, M., 2016, Design of boronic acid-attributed carbon dots on inhibits HIV-1 entry, RSC Adv., 6 (95), 9299693002.

[27] Thoo, L., Fahmi, M.Z., Zulkipli, I.N., Keasberry, N., and Idris, A., 2017, Interaction and cellular uptake functions of surface-modified carbon dot nanoparticles by J774. 1 macrophages, Cent. Eur. J. Immunol., 42 (3), 324-330.

[28] Yao, J., Feng, J., and Chen, J., 2016, External-stimuli responsive systems for cancer theranostic, Asian J. Pharm. Sci., 11 (5), 585-595.

[29] Saneja, A., Kumar, R., Arora, D., Kumar, S., Panda, A.K., and Jaglan, S., 2018, Recent advances in nearinfrared light-responsive nanocarriers for cancer therapy, Drug Discovery Today, 23 (5), 1115-1125.

[30] Xu, W., Qian, J., Hou, G., Suo, A., Wang, Y., Wang, J., Sun, T., Yang, M., Wan, X., and Yao, Y., 2017, Hyaluronic acid-functionalized gold nanorods with $\mathrm{pH} / \mathrm{NIR}$ dual-responsive drug release for synergetic targeted photothermal chemotherapy of breast cancer, ACS Appl. Mater. Interfaces, 9 (42), 36533-36547.

[31] Huang, C.Y., Ju, D.T., Chang, C.F., Reddy, P.M., and Velmurugan, B.K., 2017, A review on the effects of current chemotherapy drugs and natural agents in treating non-small cell lung cancer, BioMedicine, 7 (4), 23.

[32] Feng, T., Ai, X., An, G., Yang, P., and Zhao, Y., 2016, Charge-convertible carbon dots for imaging-guided drug delivery with enhanced in vivo cancer therapeutic efficiency, ACS Nano, 10 (4), 4410-4420.

[33] Fahmi, M.Z., Chen, J.K., Huang, C.C., Ling, Y.C., and Chang, J.Y., 2015, Phenylboronic acid-modified magnetic nanoparticles as a platform for carbon dot conjugation and doxorubicin delivery, J. Mater. Chem. B, 3 (27), 5532-5543.

[34] Yan, T., Zhong, W., Yu, R., Yi, G., Liu, Z., Liu, L., Wang, X., and Jiang, J., 2019, Nitrogen-doped fluorescent carbon dots used for the imaging and tracing of different cancer cells, RSC Adv., 9 (43), 24852-24857.

[35] Fahmi, M.Z., Haris, A., Permana, A.J., Wibowo, D.L.N., Purwanto, B., Nikmah, Y.L., and Idris, A.,
2018, Bamboo leaf-based carbon dots for efficient tumor imaging and therapy, RSC Adv., 8 (67), 38376-38383.

[36] Acharya, P.P., Genwali, G.R., and Rajbhandari, M., 2013, Isolation of catechin from Acacia catechu willdenow estimation of total flavonoid content in Camellia sinensis Kuntze and Camellia sinensis Kuntze var. assamica collected from different geographical region and their antioxidant activities, Sci. World, 11 (11), 32-36.

[37] Bhunia, S.K., Saha, A., Maity, A.R., Ray, S.C., and Jana, N.R., 2013, Carbon nanoparticle-based fluorescent bioimaging probes, Sci. Rep., 3, 1473.

[38] Saravanan, K.R.A., Prabu, N., Sasidharan, M., and Maduraiveeran, G., 2019, Nitrogen-self doped activated carbon nanosheets derived from peanut shells for enhanced hydrogen evolution reaction, Appl. Surf. Sci., 489, 725-733.

[39] Fei, H., Li, H., Li, Z., Feng, W., Liu, X., and Wei, M., 2014, Facile synthesis of graphite nitrate-like ammonium vanadium bronzes and their graphene composites for sodium-ion battery cathodes, Dalton Trans., 43 (43), 16522-16527.

[40] Choi, J., Kim, N., Oh, J.W., and Kim, F.S., 2018, Bandgap engineering of nanosized carbon dots through electron-accepting functionalization, $J$. Ind. Eng. Chem., 65, 104-111.

[41] Huang, C.C., Hung, Y.S., Weng, Y.M., Chen, W., and Lai, Y.S., 2019, Sustainable development of carbon nanodots technology: Natural products as a carbon source and applications to food safety, Trends Food Sci. Technol., 86, 144-152.

[42] Sepperer, T., and Tondi, G., 2018, Fractioning of Industrial Tannin Extract in Different Organic Solvents, Das 12. Forschungs forum der österreichischen Fachhochschulen (FFH), 4-5 April 2018, Campus Urstein, Salzburg, Austria.

[43] Jia, X., Li, J., and Wang, E., 2012, One-pot green synthesis of optically $\mathrm{pH}$-sensitive carbon dots with up conversion luminescence, Nanoscale, 4 (18), 5572-5575.

[44] Rawangkan, A., Wongsirisin, P., Namiki, K., Iida, K., Kobayashi, Y., Shimizu, Y., Fujiki, H., and 
Suganuma, M., 2018, Green tea catechin is an alternative immune checkpoint inhibitor that inhibits PD-L1 expression and lung tumor growth, Molecules, 23 (8), E2071.

[45] Yang, C.S., and Wang, H., 2016, Cancer preventive activities of tea catechins, Molecules, 21 (12), E1679.

[46] Negri, A., Naponelli, V., Rizzi, F., and Bettuzzi, S., 2018, Molecular targets of epigallocatechin-Gallate (EGCG): A special focus on signal transduction and cancer, Nutrients, 10 (12), E1936.
[47] Fahmi, M.Z., Wibowo, D.L.N., Sakti, S.C.W., Lee, H.V., and Isnaeni, 2020, Human serum albumin capsulated hydrophobic carbon nanodots as staining agent on HeLa tumor cell, Mater. Chem. Phys., 239, 122266.

[48] Ansari, A.A., Hasan, T., Syed, N., Labis, J., and Alshatwi, A.A., 2017, In-vitro cytotoxicity and cellular uptake studies of luminescent functionalized core-shell nanospheres, Saudi J. Biol. Sci., 24 (6), 1392-1403. 